\title{
Dominance and growth of Diplodus sargus (Pisces: Sparidae) in small captive groups
}

\author{
Ana Ribeiro Gonçalves ${ }^{a, b, *}$, Liliana Carvalho de Sousa ${ }^{\mathrm{b}}$, Vitor Carvalho Almada ${ }^{\mathrm{a}}$ \\ a Unidade de Investigação em Eco-Etologia, ISPA-IU, R. Jardim do Tabaco 34, 1149-041 Lisbon, Portugal \\ b Instituto de Ciências Biomédicas Abel Salazar, Largo Prof. Abel Salazar 2, 4099 Porto, Portugal
}

\section{A R T I C L E I N F O}

\section{Article history:}

Accepted 15 January 2012

Available online 8 February 2012

\section{Keywords:}

Agonistic behavior

Condition factor

Growth

Hierarchy

Sparidae

\begin{abstract}
A B S T R A C T
The dominance hierarchies and the growth rate of the commercially important fish Diplodus sargus were assessed in this study. Specifically, we tested the hypothesis that, if stable dominance orders were established, dominant fish would grow faster and show better condition factors than losers at the end of the experiment. Eight groups of six individuals were followed for 6 weeks and, for each group, we measured the linearity of the hierarchies on a weekly basis, and the week to week stability of the hierarchical structures. These dominance structures were linear and stable from week to week. We found no significant correlation between the dominance index with either growth rate or final condition factor. Thus, in short time windows over few weeks, aggressive competition seems not to cause differences in growth, although effects at a longer term like those induced by stress cannot be ruled out.
\end{abstract}

(c) 2012 Elsevier B.V. All rights reserved.

\section{Introduction}

In southwest European Atlantic and in the Mediterranean the white seabream Diplodus sargus (Linnaeus, 1758) (Pisces: Sparidae) reaches a high market value (D'Anna et al., 2004; FAO, 2004). Although the stocks do not support large scale in industrial fishing this inshore species is an important source of income for local fisherman in many countries (FAO, 2004). Several attempts have been made to introduce the species in aquaculture (Abellan and Garcia-Alcazar, 1995; Bodington, 2000; Kentouri et al., 1995). Many of these attempts to fish farm the white seabream have been hindered by the slow growth of the species in captivity after the first year of life. In many cases, this slow growth reduces the profitability of commercial

\footnotetext{
* Corresponding author at: Unidade de Investigação em Eco-Etologia, ISPA-IU, R. Jardim do Tabaco 34, 1149-041 Lisbon, Portugal. Tel.: +351 218811 700; fax: +351218860954.

E-mail addresses: agoncalves@ispa.pt, anagnvs@yahoo.com (A.R. Gonçalves).
}

production (D'Anna et al., 2004). D. sargus displace very high levels of aggression in captivity (Caballero and CastroHdez, 2003; Castro and Caballero, 1998; Karakatsouli et al., 2007), and several authors raise the hypothesis of the slowing of growth being caused by an excess of behaviors related to aggression and escape (Caballero and CastroHdez, 2003; Karakatsouli et al., 2007; Papoutsoglou et al., 2006). This link is far from being proved, as several other factors may also reduce growth. For instance, a study on the response of white seabream to different stocking densities revealed the presence of a chemical communication among stressed fish (Olivotto et al., 2002). Thus, in closed systems, where fish are highly confined and the water circulation is limited when compared with open systems, the chemicals generated by induced stress may affect the growth rate.

Previous studies on the aggressive behavior of $D$. sargus in aquaria (Castro and Caballero, 1998; Caballero and Castro-Hdez, 2003) showed that, in small captive groups, dominance hierarchies tended to develop generating asymmetries among group members. According to Castro and Caballero (1998), one or a few individuals win most contests while others become chronic losers. 
Typically, it is assumed that in a conflict situation fish compete for some resources: priority of access to food, shelter, etc. (Huntingford and Turner, 1987). In this scenario, winners are predicted to gain advantages over losers in survival, growth or breeding success (Harwood et al., 2003). The study of Castro and Caballero (1998) showed a peckdominance hierarchy in groups of four white seabream. Our study gives a more detailed analysis of the structure of dominance orders in captive groups of six white seabream assessing the linearity and stability of such hierarchies. Moreover, the present study is apparently the first in which the behavior of individual fish in each group is combined with measurements of weight and length of the same individuals before and after the observation period for a time window known. Thus, the position of each fish in its group and the specific growth rate and condition of the same fish can be assessed. Our hypothesis was that dominant fish display a higher specific growth rate and reach better condition factor than losers. If this hypothesis turns to be supported, it could point to a role of aggression in the overall reduced growth rate in captive groups of $D$. sargus.

\section{Materials and methods}

\subsection{Subjects and maintenance}

Fish used in the present study were collected at Ericeira (Portugal, $38^{\circ} 58^{\prime} \mathrm{N}, 9^{\circ} 25^{\prime} \mathrm{W}$ ) during low tide in early July 1998. Forty eight fish, with a mean initial body weight $( \pm \mathrm{SD})$ of $3.10 \pm 1.89 \mathrm{~g}$ and a standard length $( \pm \mathrm{SD})$ of $3.8 \pm 1.31 \mathrm{~cm}$, were distributed in eight aquaria (six fish per tank) of $80 \mathrm{~cm} \times 30 \mathrm{~cm} \times 40 \mathrm{~cm}$ with a layer of sand on the bottom. The fish were fed daily with mussels ad libitum $30 \mathrm{~min}$ before video recording, and were kept at $21 \pm 2{ }^{\circ} \mathrm{C}$ with a photoperiod of $12 \mathrm{~L}: 12 \mathrm{D}$. Illumination was provided by $14 \mathrm{~W}$ fluorescent lamps. Experimental tanks were supplied with a filtering system and constant aeration. Artificial sea water was prepared with a salinity of 30 ppt (Tetramarine sea salt ${ }^{\circledR}$ Germany).

\subsection{Behavioral observations}

Behavioral observations began after 1 week of acclimation period. Behavioral observations were video recorded daily in 60 min sessions for each tank, between 9:00 h and 13:00 h, during 6 weeks (5 days per week) with a Canon (MV650i) camera. The camera was placed so that all members of the group were recorded simultaneously. Ten min of focal observations (sensu Martin and Bateson, 1993) for all members of each group were extracted from the video records and analyzed at a daily basis, comprising an observation effort of $5 \mathrm{~h}$ per group each week.

At each observation, the agonistic interactions, their outcomes and the identity of the participants were recorded. The fish were individually recognized by their relative size and by natural marks on their body. We considered that an agonistic interaction occurs when one or more of the following patterns were recorded: approach, withdrawal, threatening, chasing, fleeing, charging and bite/butt. An individual was considered a loser when it retreated, adopted a submissive posture, or fled from the opponent. For a detailed description of each behavior pattern see Estabrook et al. (2002). After 6 weeks of behavioral observations fish were again measured and weighted and the specific growth rate and the dominance index of each individual were determined.

\subsection{Data analysis}

Data analyses were performed using STATISTICA for Windows version 4.5 Software package (StatSoft Inc., 1993). The Shapiro-Wilk test was performed in STATISTICA to test for normal distribution.

Based on the outcomes of the agonistic interactions, matrices were constructed for each group, both on a weekly basis and for the entire observation period. The rank order of individuals was determined by the analysis of these sociometric matrices and then reordered according to the procedure described by De Vries et al. (1993).

To characterize the structure of small groups of juvenile white seabream we assessed the linearity and stability of dominance structures. Linearity was measured according to Landau's linearity index (Landau, 1951), with the correction proposed by Nelissen (1986) for ties. Stability of dominance structures in consecutive weeks was measured by Spearman rank correlations, while the stability for the entire observation period was assessed with Kendall's coefficient of concordance.

The dominance index was computed as $V /(V+D)$, where number of victories $(V)$ over the total number of interactions - number of victories plus number of defeats $(V+D)$ in which the fish participated (see Winberg et al., 1991; Gomez-Laplaza and Morgan, 1993; Oliveira and Almada, 1996a,b). The relationship between dominance index and rank was assessed using a Spearman correlation. This correlation was also applied to study the relationship between each fish initial size and its dominance index, as well as between the total interactions that each fish initiated and its dominance index.

The intensity of each interaction was classified as low (L), if it involved threatening behavior, or high $(\mathrm{H})$, if it involved charging behavior. The proportion of $\mathrm{H}$ in relation to $\mathrm{L}$ intensity behaviors was calculated for each fish for the entire observation period. To assess the relationship between each fish initial size and its $\mathrm{H} / \mathrm{L}$ intensity behavior proportions a Spearman correlation was performed.

Individual specific growth rates for length and weight were calculated as $100 \times[\operatorname{Ln}($ final measurement) - Ln(initial measurement)]/(duration of experiment in days), according to Jobling (1994). To assess the relationship between dominance status and growth, a Spearman correlation between dominance index and specific growth rate for length $\left(\mathrm{SGR}_{\mathrm{L}}\right)$ as well as between dominance index and specific growth rate for weight $\left(\mathrm{SGR}_{\mathrm{W}}\right)$ was used. A significant correlation between dominance index and specific growth rate $\left(\mathrm{SGR}_{\mathrm{L}}\right.$ or $\left.S G \mathrm{R}_{\mathrm{W}}\right)$ will reveal unequal growth of dominant and subordinate fish.

An index of each fish condition was also calculated as $W /\left(\mathrm{SL}^{3}\right) \times 1000$. To assess the relationship between the dominance status of each fish and its final condition, a Spearman correlation between dominance index and final condition factor was performed. 
Bonferroni corrections were applied whenever the same variable was used in multiple tests (Holm, 1979). Multiple correlations were considered to be significant for $P$-values $<0.01$ after Bonferroni corrections.

\subsection{Ethical note}

The works described were conducted in accordance to national legal standards on protection of animals used for experimental purposes.

\section{Results}

When analyzing dominance hierarchies, a hierarchy was considered linear when the Landau's index $(h)$ was equal or greater than 0.9 , as proposed by Chase (1974). Seven out of eight groups studied displayed linear hierarchies $(h>0.97)$ (Fig. 1$)$.

Further, we tested if the dominance structures were stable along the observation period. A dominance structure was considered stable between two consecutive weeks if the Spearman rank correlation $\left(r_{\mathrm{s}}\right)$ was equal or greater than 0.7 (Oliveira and Almada, 1996a). We concluded that, for most groups, the dominance structure was relatively stable. Furthermore, two groups yielded a stable structure in 5 , three groups in 3 , and three groups in 1 , out of 5 transitions (Fig. 2). Kendall's coefficient of concordance showed that dominance structures were stable for the entire observation period ( $W=1, P<0.05$ for all groups).

We investigated the relationship between the rank of each fish and its index of social dominance. There was a positive correlation between these two variables $\left(r_{s}=0.839, P<0.001, n=46\right)$. This suggests that the individual's overall success in aggressive interactions is a reliable predictor of its position in the rank order of the group. Interestingly, this success does not appear to depend on the initial size of individuals, since we found no correlation between their initial size and dominance index $\left(r_{\mathrm{s}}=0.401, P=0.058, n=46\right)$. However, the proportion of $\mathrm{H} /$ L intensity behaviors for each specimen was significantly correlated with its initial size $\left(r_{\mathrm{s}}=-0.717, P<0.001, n=46\right)$.

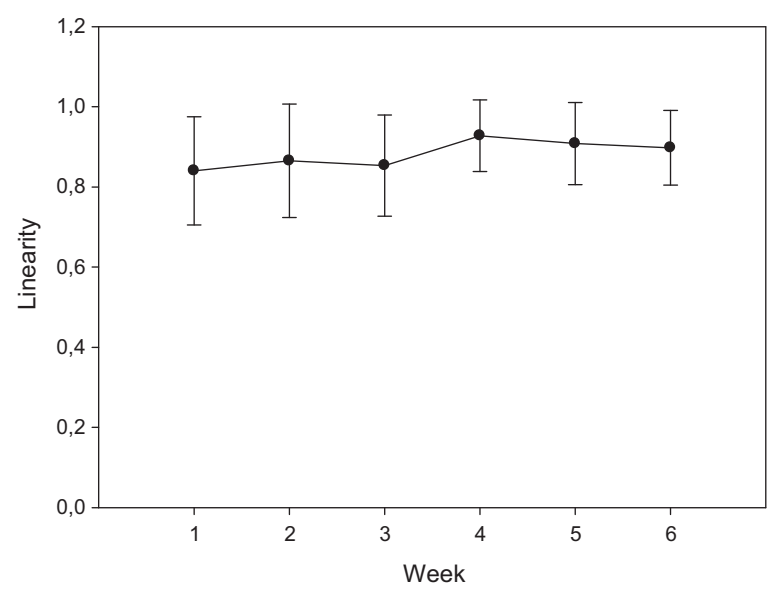

Fig. 1. Juvenile Diplodus sargus in captivity. Temporal variation of the Landau's indexes $(h)$ along six weeks.

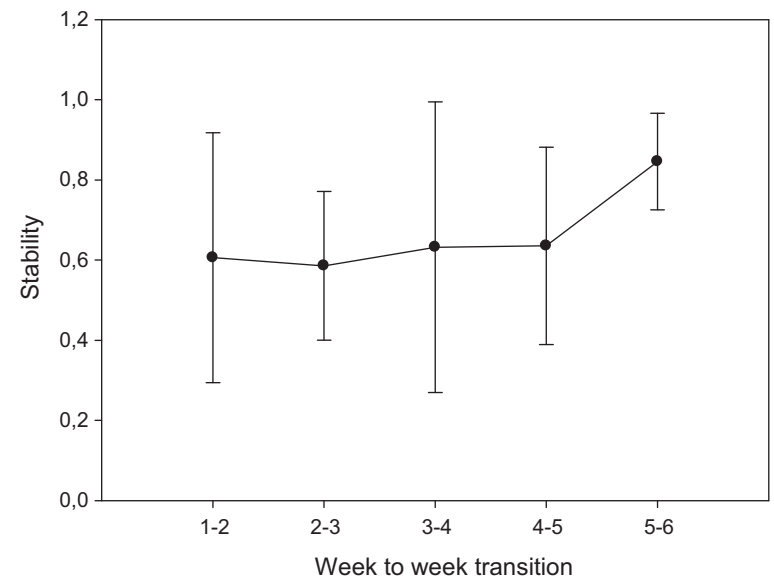

Fig. 2. Juvenile Diplodus sargus in captivity. Temporal variation of the Spearman correlation $\left(r_{\mathrm{s}}\right)$ along the consecutive weeks.

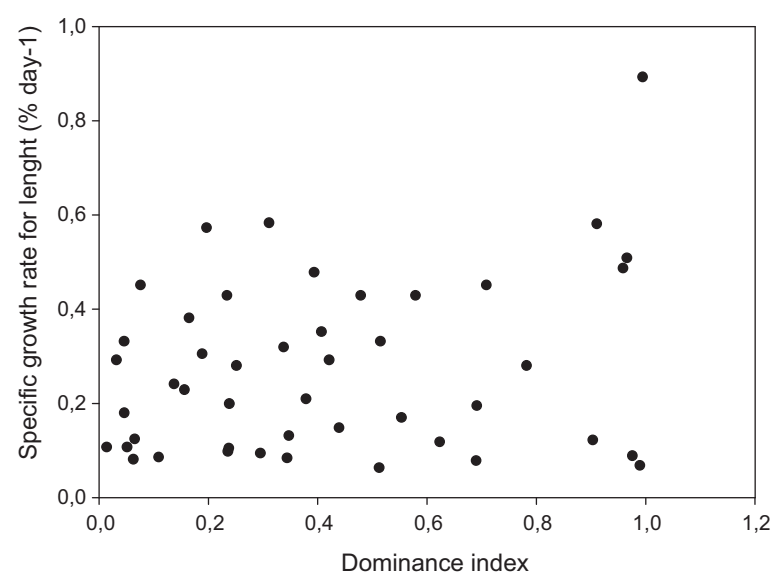

Fig. 3. Juvenile Diplodus sargus in captivity. Specific growth rate for length of individual fish in relation to dominance index.

The dominance index was positively correlated with the number of aggressive interactions initiated by an individual $\left(r_{\mathrm{S}}=0.910, P<0.001, n=46\right)$ and did not appear to influence its $\operatorname{SGR}_{\mathrm{L}}\left(r_{\mathrm{S}}=0.134, P=0.373, n=46\right)$ (Fig. 3 ), nor its $\mathrm{SGR}_{\mathrm{W}}$ $\left(r_{\mathrm{S}}=-0.084, P=0.578, n=46\right)$ (Fig. 4) nor its final "condition" $\left(r_{\mathrm{S}}=-0.228, P=0.128, n=46\right)$. This lack of correlation between dominance index and growth rates revealed that unequal growth of dominant and subordinate fish was not present in this experiment. The growth performance values of white seabream show an improvement of fish's size and condition along the 6 weeks of study (Table 1).

\section{Table 1}

Growth performance of juvenile Diplodus sargus reared in small groups for six weeks.

\begin{tabular}{lcll}
\hline & Mean $( \pm$ SD $)$ & Median & Quartile range \\
\hline Initial standard length $(\mathrm{cm})$ & $3.80 \pm 1.31$ & 3.30 & 1.9 \\
Initial body weight $(\mathrm{g})$ & $3.10 \pm 1.89$ & 2.60 & 2.6 \\
Initial condition factor & $32.0 \pm 6.88$ & 30.5 & 6.2 \\
Final standard length $(\mathrm{cm})$ & $4.24 \pm 1.33$ & 3.95 & 1.5 \\
Final body weight $(\mathrm{g})$ & $3.50 \pm 3.49$ & 2.40 & 3.1 \\
Final condition factor & $38.2 \pm 7.94$ & 36.3 & 12.1 \\
\hline
\end{tabular}

$\mathrm{SD}$, standard deviation. 


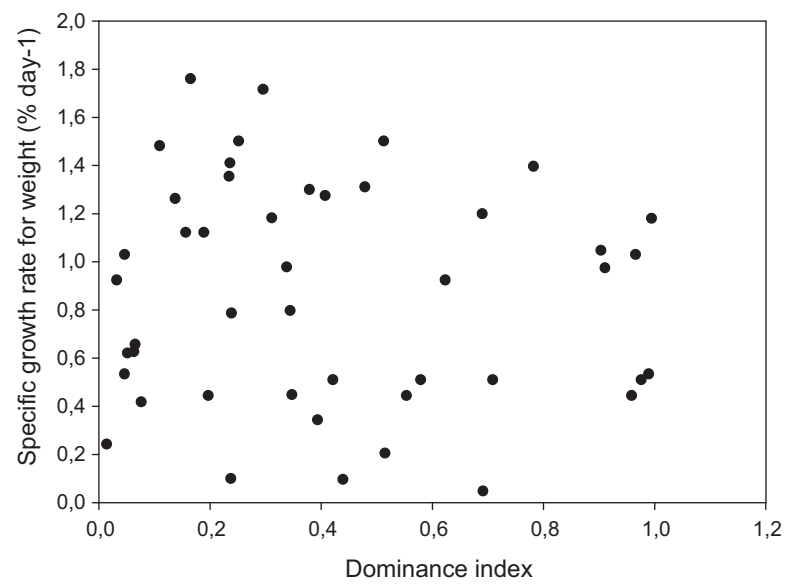

Fig.4. Juvenile Diplodus sargus in captivity. Specific growth rate for weight of individual fish in relation to dominance index.

\section{Discussion}

Castro and Caballero (1998) found hierarchies in which fish carried out more attacks on the individual whose subordination level is immediately inferior to their own. In the present study, that finding was corroborated but several other features of the social hierarchies could be identified and characterized quantitatively, namely the predominance of linear structures, the level of stability from week to week and the clear relationship between the number of attacks initiated by a fish and its position in the group. Indeed, in the present study, linear hierarchies were found in 7 out of 8 groups and they were stable from week to week. Moreover, the dominance index was a very good predictor of rank order. Thus, the picture that emerges is one of highly structured groups with very predictable patterns of interactions among individuals.

The role of size in the organization of agonistic interactions has been documented for a wide variety of fish (Abbott et al., 1985; Beaugrand et al., 1996). However, our results showed no relationship between initial size and dominance. The failure to detect such an effect in our study may mean that: (1) size is irrelevant in the hierarchy formation in D. sargus, or (2) size differences were not sufficiently large to determine the ranks of fish in the groups observed. Nevertheless, we found that the proportion of $\mathrm{H} / \mathrm{L}$ intensity behaviors was related to the fish initial size. This suggests an effect of fish relative size on the intensity of agonistic behavior. Apparently large individuals perform preferentially low intensity behaviors that seemed to result in the withdrawal of the opponent. In order to achieve the same, small individuals had to display high intensity behaviors.

Turning now to the possible consequences of dominance on growth rate and condition, we found no relationships between dominance index and specific growth rates $\left(\mathrm{SGR}_{\mathrm{L}}\right.$ or $\left.\mathrm{SGR}_{\mathrm{W}}\right)$ or between dominance index and condition factor at the end of the experiment. Such a lacking correlation between dominance index and growth rate was previously reported by Cutts et al.(2001) in groups of Arctic charr Salvelinus alpinus. The costs of high ranking fish to establish dominance with energy expenditure during attacking and chasing (Cutts et al., 2001) as well as reduced time available for feeding (Harwood et al., 2002) may be similar to the costs of escapes and multiple defeats in subordinate fish. Especially in captive fish with simplified environments, the advantage of dominance is unclear. In such an environment, being dominant does not necessarily mean having more resources; in our experimental design, feeding was delivered in quantities that allowed all fish to eat simultaneously.

For most fish there was positive growth and the condition factor did not deteriorate when compared with the corresponding values before the observations. However, the $\mathrm{SGR}_{\mathrm{W}}\left(0.86 \% \mathrm{day}^{-1}\right)$ obtained in our study was lower than those observed previously for white seabream. Previous studies on white seabream growth in realistic rearing conditions reported $\mathrm{SGR}_{\mathrm{W}}$ of $1.49 \% \mathrm{day}^{-1}$ (Abellan and Garcia-Alcazar, 1995) using a stocking density of $4.5-5.0 \mathrm{~kg} \mathrm{~m}^{-3}$ in tanks of 1 and $2 \mathrm{~m}^{3}$ with fish weighing about $3 \mathrm{~g}$ each. Papoutsoglou et al., 2006 obtained a SGR of $1.06 \%$ day $^{-1}$ using a stocking density of $4.8-9.8 \mathrm{~kg} \mathrm{~m}^{-3}$ but in small aquaria (88.4 L capacity) and using fish with mean initial body weights of $( \pm S D)$ of $14.3 \pm 0.10 \mathrm{~g}$. These differences may be explained by variations in body size as well as variations in duration time of experiment between all studies. Moreover, these studies used commercial diet which may be better suited for seabream growth than our mussel feed. Both studies used more fish per tank than our work although with very different tank sizes. It would be interesting to test in the future if groups with more fish tend to show "diluted" effects of aggression by dominant fishes as it is distributed by more individuals as reported for instance for cichlid fish (Baerends and Baerends-van Roon, 1950). The variation of condition factor is unknown for the previous studies and this could be another important parameter to compare. The present work points to the fact that a possible effect of aggressive competition on growth does not seem to differ between dominant and subordinate fish in relatively short time windows. As stated in the introduction, the problem of growth decrease in $D$. sargus may have a multitude of causes besides aggression. In closed systems and with adequate feeding formulas, accumulation of substances that affect growth or the need for more space and exercise are candidates to be instrumental in growth decline. On the other hand, long term studies are needed to evaluate the role of aggression, in particular, experiments in conditions that mimic more adequately aquaculture systems.

\section{Conclusions}

In our view, the present work argues against aggressive competition as a major cause of unequal growth in groups that are kept for some weeks. Nevertheless, this unequal growth may be stress induced and changes in winners and losers may only be revealed in longer time scales. It is important to state that the duration of the observation period may affect the results as some processes involved in growth changes may operate at a time scale longer than the one used in this paper. Thus, our conclusions may not hold in long time experiments. We decided to perform this study assuming the limitations of the observation period 
as a first step to investigate social status, growth and condition. Our decision was motivated by our experience that fish in setups of this kind are very aggressive. Thus, we tried to reach a balance between getting data and respecting the welfare of the fish as much as possible. In the future more prolonged studies may be envisaged when setups which minimize aggression and stress are available. Future studies should combine long term monitoring of aggression, stress indicators and growth in fish densities and areas comparable to the ones used in fish farms.

As a final note it is worth mentioning that, in spite of the considerable literature on aggression of white seabream in artificial conditions, there are no data available on aggression of $D$. sargus in natural situations. This is an area of study that may shed light on many of the issues raised by the maintenance of this species in captivity.

\section{Acknowledgments}

This research was financially supported by Fundação para a Ciência e Tecnologia with a PhD research grant given to Ana Ribeiro Gonçalves (SFRH/BD/42226/2007) and through the pluriannual scheaming fund attributed to Unidade de Investigação em Eco-Etologia (\#331/94). The authors thank Clara Amorim, Pedro Vale and Sara Francisco for their comments on the manuscript.

\section{References}

Abbott, J.C., Dunbrack, R.L., Orr, C.D., 1985. The interaction of size \& experience in dominance relationships of juvenile steelhead trout (Salmo gairdneri). Behaviour 92, 241-253.

Abellan, E., Garcia-Alcazar, A., 1995. Pre-growth and growth experiences with white seabream (Diplodus sargus sargus, Linnaeus, 1758) and sharpsnout seabream (Diplodus puntazzo, Cetti, 1977). Cah. Options Mediterr. 16, 57-63.

Baerends, G.P., Baerends-van Roon, J.M., 1950. An introduction to the study of cichlid fishes. Behaviour (Suppl. 1), 1-242.

Beaugrand, J.P., Payette, D., Goulet, C., 1996. Conflict outcome in male green swordtail fish dyads (Xiphophorus helleri): interaction of body size, prior dominance/subordination experience, and prior residency. Behaviour 133, 303-319.

Bodington, P., 2000. Enterprise experiences in the culture of new sparids. Cah. Options Mediterr. 47, 135-139.

Caballero, C., Castro-Hdez, J.J., 2003. Effect of competitor density on the aggressiveness of juvenile white seabream (Diplodus sargus cadenati de la Paz, Bauchot and Daget, 1974). Aggress. Behav. 29, 279-284.

Castro, J.J., Caballero, C., 1998. Dominance structure in small groups of white seabream (Diplodus sargus cadenati de la Paz, Bauchot and Daget 1974). Aggress. Behav. 24, 197-204.
Chase, I.D., 1974. Models of hierarchy formation in animals societies Behav. Sci. 19, 374-382.

Cutts, C.J., Adams, C.E., Campbell, A., 2001. Stability of physiological and behavioural determinants of performance in Arctic char (Salvelinus alpinus). Can. J. Fish. Aquat. Sci. 58, 961-968.

D’Anna, G., Giacalone, V.M., Badalamenti, F., Pipitone, C., 2004. Releasing of hatchery-reared juveniles of the white seabream Diplodus sargus (L., 1758) in the Gulf of Castellammare artificial reef area (NW Sicily). Aquaculture 233, 251-268.

De Vries, H., Netto, W.J., Hanegraaf, P.L.H., 1993. Matman: a program for the analysis of sociometric matrices and behavioural transitions matrices. Behaviour 125, 157-175.

Estabrook, G.F., Almada, V.C., Almada, F.J., Robalo, J.I., 2002. Analysis of conditional contingency using ACTUS2 with examples from studies of animal behavior. Acta Ethol. 4, 73-80.

FAO, 2004. State of World Fisheries and Aquaculture 2004. FAO, Rome $153 \mathrm{pp}$.

Gomez-Laplaza, L.M., Morgan, E., 1993. Social isolation, aggression and dominance in attacks in juvenile angelfish, Pterophyllum scalare. Aggress. Behav. 19, 213-222.

Harwood, A.J., Armstrong, J.D., Griffiths, S.W., Metcalfe, N.B., 2002. Sympatric association influences within-species dominance relations among Atlantic salmon and brown trout. Anim. Behav. 64, 85-95.

Harwood, A.J., Armstrong, J.D., Metcalfe, N.B., Griffiths, S.W., 2003. Does dominance status correlate with growth in wild stream-dwelling Atlantic salmon (Salmo salar)? Behav. Ecol. 14, 902-908.

Huntingford, F., Turner, A., 1987. Animal Conflict. Chapman \& Hall, London.

Holm, S., 1979. A simple sequentially rejective multiple test procedure Scandinavian. J. Stat. 6, 65-70.

Jobling, M., 1994. Fish Bioenergetics. Chapman \& Hall, London.

Karakatsouli, N., Papoutsoglou, S.E., Manolessos, G., 2007. Combined effects of rearing density and tank colour on the growth and welfare of juvenile white seabream Diplodus sargus L. in a recirculating water system. Aquac. Res. 38, 1152-1160.

Kentouri, M., Papandroulakis, N., Divanach, P., 1995. Specific diversification in Greek finfish mariculture. Cah. Options Mediterr. 14, 129-136.

Landau, H.G., 1951. On dominance relations and the structure of anima societies. I. Effect of inherent characteristics. Bull. Math. Biophys. 13 $1-19$.

Martin, P., Bateson, P., 1993. Measuring Behaviour. An Introductory Guide, 2nd edn. Cambridge University Press, Cambridge.

Nelissen, M.H.J., 1986. The effect of tied rank numbers on the linearity of dominance hierarchies. Behav. Process. 12, 159-168.

Oliveira, R.F., Almada, V.C., 1996a. On the (In)stability of dominance hierarchies in the cichlid fish Oreochromis mossambicus. Aggress. Behav. 22, 37-45.

Oliveira, R.F., Almada, V.C., 1996b. Dominance hierarchies and social structure in captive groups of the Mozambique tilapia Oreochromis mossambicus (Teleostei Cichlidae). Ethol. Ecolog. Evol. 8, 39-55

Olivotto, I., Mosconi, G., Maradonna, F., Cardinali, M., Carnevali, O., 2002 Diplodus sargus interrenal-pituitary response: chemical communication in stressed fish. Gen. Comp. Endocrinol. 127, 66-70.

Papoutsoglou, S.E., Karakatsouli, N., Pizzonia, G., Dalla, C., Polissidis, A., Papadopoulou-Daifoti, Z., 2006. Effects of rearing density on growth, brain neurotransmitters and liver fatty acid composition of juvenile white sea bream Diplodus sargus L. Aquac. Res. 37, 87-95.

Winberg, S., Nilsson, G.E., Olsên, K.H., 1991. Social rank and brain levels of monoamines and monoamine metabolites in Arctic charr, Salvelinus alpinus (L.). J. Comp. Physiol. (A) 168, 241-246. 